\title{
Degradation of a Dental Filling Material After High Caries Challenge
}

\author{
Márcio Antonio Paraizo ${ }^{\mathrm{a} *}$, Luis Claudio Mendes ${ }^{\mathrm{b}}$, Ailton de Souza Gomes ${ }^{\mathrm{b}}$, \\ Mauro Sayão de Miranda ${ }^{\mathrm{a}}$, Ana Claudia Fernandes Amaral ${ }^{\mathrm{c}}$ \\ ${ }^{\text {a }}$ FOUFRJ - Hospital Universitário, Cidade Universitária, \\ Ilha do Fundão, 21945-970 - RJ, Brazil \\ ${ }^{\mathrm{b}}$ IMA - UFRJ - C. T., Bl. J, Cidade Universitária, \\ Ilha do Fundão, 21945-970 - Rio Janeiro - RJ, Brazil \\ ${ }^{\mathrm{c}}$ FIOCRUZ - Farmanguinhos, Av. Brasil, 4036, Rio de Janeiro - RJ, Brazil
}

Received: October 29, 2003; Revised: June 9, 2004

\begin{abstract}
New types of copolymers using monomers which form inorganic polymers network (glasslike) and organic networks have been developed, known as ormocers. The aim of this work was to study how a particular dental filling material is degraded when subjected to a caries challenge by using low $\mathrm{pH}$ solutions. The supernadants were studied by HPLC to detect the presence of molecules from the resin, while the changes of the material surface were evaluated by contact angle. An organic modified ceromer (ormocer) called Definite ${ }^{\circledR}$ (Degussa ) was tested. Samples were built following manufacturer's instructions. After $\mathrm{pH}$ cycles, solutions were injected in a HPLC. The contact angle was obtained using a goniometer after and before the cycles. HPLC results showed material degradation, only detected in acid solutions. Bis-GMA and TEGDMA were detected in Definite ${ }^{\circledast}$ residues. Means and S.D. of contact angle were $(\mathrm{p}<0,05)$ : baseline: $85 \cdot 16^{\circ} \pm$ $3.90^{\circ}$ and after $\mathrm{pH}$ cycles: $69.77^{\circ} \pm 7.12^{\circ}$. The authors concluded that an ormocer filling material degraded on a caries simulated environment.
\end{abstract}

Keywords: Composite resin, Degradation, HPLC, Contact angle

\section{Introduction}

Usually, the organic matrix of a dental composite is based on cross-linking dimethacrylates like 2,2-bis[4-(2-hydroxy-3methacryloyloxypropyl)phenyl]propane (Bis-GMA), 1,6-bis[2-methacryloyloxycarbonylamino]-2,4,4-trimethylhexane (UDMA) or triethyleneglycol dimethacrylate (TEGDMA) ${ }^{1}$. Some problems may influence the efficiency of these materials, as polymerization shrinkage, water sorption, and uncomplete double bonds conversion ${ }^{2}$.

From $25 \%$ to $50 \%$ of methacrylate groups remain unreacted after light curing ${ }^{3}$. This uncured material may represent a potential toxicological risk for personnel and patients ${ }^{4}$.

Ormocers are been studying as possible substitutes of convencional composite resins based on Bis-GMA. Compared to the usual composites, the amount of dimethacrylate monomers has been reduced by the use of methacrylatefunctionalized polysiloxanes as the main component of the matrix, reducing the chances of allergic reactions ${ }^{5}$.

The aim of this study was to evaluate the degradation

*e-mail: marcioparaizo@uol.com.br

Article presented at the II SBPMat, Rio de Janeiro - RJ, 26-29 de Outubro/ 2003 suffered by dental filling resin based on ormocer system after a caries challenge, by contact angle and high performance liquid cromatograph (HPLC).

\section{Experimental}

The ormocer resin Definite ${ }^{\circledR}$ (colour B2, allot 0996226) was used in this work. The organic composition was characterized using Nuclear Magnetic Resonance (NMR). The degree of monomeric conversion was accomplished using the Fourier Transform Infrared Spectrometry (FTIR).

Five specimens were built in a $30 \times 6 \times 2 \mathrm{~mm}$ Teflon mold, following manufacturer instructions. Samples were submitted to $\mathrm{pH}$ cyclic variations to simulate a high caries challenge during 14 days as described by Modesto et al. ${ }^{6}$. The solutions $\mathrm{pH}$ were adjusted for demineralized $(\mathrm{pH}=4.3)$ and buffer ( $\mathrm{pH}=7.0$ ) specimens, respectively. After the $\mathrm{pH}$ cycle, the incubated solution was dryed by liofilization $\left(-70^{\circ} \mathrm{C}\right.$ and $6 \mathrm{~Pa}$ ). The remaining residues were dissolved in methanol 
and the resultant solutions, centrifuged. Ten microliters of each solution were used in HPLC analysis.

HPLC analysis was accomplished in a Shimadzu chromatograph equipped with UV-VIS detector, column of silica of reverse phase C-18 Merck Lichrosorb 4,6 × $250 \mathrm{~mm} \times 5 \mu \mathrm{m}$. The mobile phase conditions were the following: water (phase A)/acetonitrile (phase B), with variation of 3 to $70 \%$ of the phase B in $50 \mathrm{~min}$. The chromatograms were reported for a UV wavelength of $220 \mathrm{~nm}$. Samples of Bis-GMA, TEGDMA, and UDMA were injected. The HPLC peaks of the degraded and the references samples were compared.

The contact angle $(\theta)$ was evaluated before/after the $\mathrm{pH}$ cycle using a goniometer NRL A-100 - Ramé Hart, at $23{ }^{\circ} \mathrm{C}$ and $50 \%$ of relative humidity. Four drops of distilled water $(0,006 \mathrm{ml})$ were measured on different areas on the surface of the polymerized specimen after 6 min (10 measurements giving $20 \mathrm{~s}$ intervals for each drop).

\section{Results and Discussion}

The chromatograms of the solutions of demineralized and buffer samples are presented in Fig. 1. Figure 2 (top) shows the chromatogram of Bis-GMA sample which main retention time (MRT) is of $48.66 \mathrm{~min}$ (peak 7). At the middle is presented UDMA sample (MRT $=49.33 \mathrm{~min}$ - peak 5). At the bottom of Fig. 2 the TEGDMA sample (MRT = 39.58 min -peak 3 ). The Definite ${ }^{\circledR}$ chromatograms of simulated samples in different solutions are shown in Fig. 3. At the top is presented the solution of demineralized sample. The comparison of these retention times with those found in the known samples made possible to identify similar peaks in TEGDMA ([3] RT = $40.14 \mathrm{~min}$ ) and Bis-GMA ([6] $\mathrm{RT}=48.26$, [7] $54.96 \mathrm{~min}$ ). At the bottom of the Fig. 3, the buffer sample solution revealed profile similar to the standard buffer solution without any similarity with those known monomers samples. From the results, we conclude that in the acid solution it occurred a dissolution of the residual monomer of the polymerized specimen while in buffer solution this fact did not occur, according to Söderholm ${ }^{7}$ and Asmussem ${ }^{8}$.

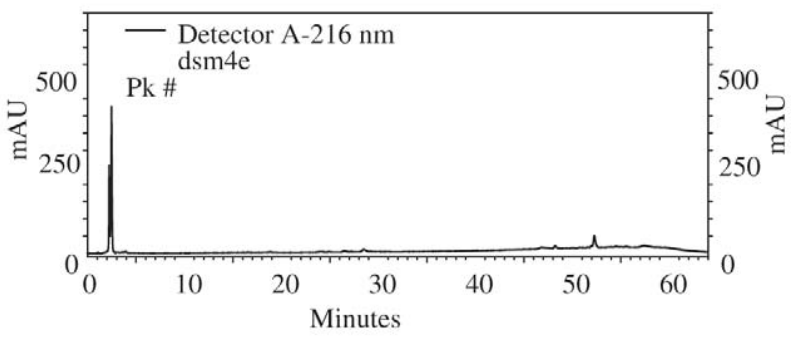

(a)
Several factors should contribute to the process of elution from dental composites ${ }^{9}$. One factor is the low conversion degree, and the FTIR showed $45.70 \%$ for Definite with $2 \mathrm{~mm}$ depth. These residual monomers can make the polymeric matrix more susceptible to degradative reactions. Indeed, during the cure of resin, dimethyl-methacrylate monomer molecules such as Bis-GMA, TEGDMA and UEDMA croos-link and form a three dimensional net structure. However, some of the monomer molecules remain unreacted within the network, while the majority is tied together with both methacrylate groups. Because of that structure, only monomer molecules that do not participate in the network formation can be leached. Monomer molecules that are smaller and flexible have fewer polar groups, and shorter and more flexible pendant groups. These molecules should be able to difuse easier through the polymer network than larger and more complex monomer molecules ${ }^{10}$. The gradual degradation changes the net microstructure forming porosities, and through this way, residual monomers and degradation by products are released, which may lead to an erosion and mass loss ${ }^{11}$.

Another factor is the chemistry of the solvent. Certain organic acids of oral biofilm induced a softening of BisGMA-composites, probably by the permeation and extraction of substances in Bis-GMA and UDMA polymers ${ }^{9}$.

The results of contact angle test were treated by ANOVA and Student-Neuman-Keuls test, being of $85.16^{\circ} \pm 3.90^{\circ}$ before the $\mathrm{pH}$ cycles and of $69.77^{\circ} \pm 7.12^{\circ}$ after the $\mathrm{pH}$ cycles, showing significant statistic difference in wettability $(p<0,05)$. The characteristic of wettability of the adhesive depends on its viscosity and also on the adherent surface irregularities ${ }^{12}$. Söderholm et al. ${ }^{7}$ have related a surface variation in composites and the degradation provoked by several solvents.

Although ormocer's best properties of biocompatibility have been related by Haas \& Wolter ${ }^{5}$ and Moszner ${ }^{1}$, it wasn't noted in Definite ${ }^{\circledR}$. Composite filling materials based on the ormocer technology currently available in the market are not pure ormocer systems. To obtain good handling prop-

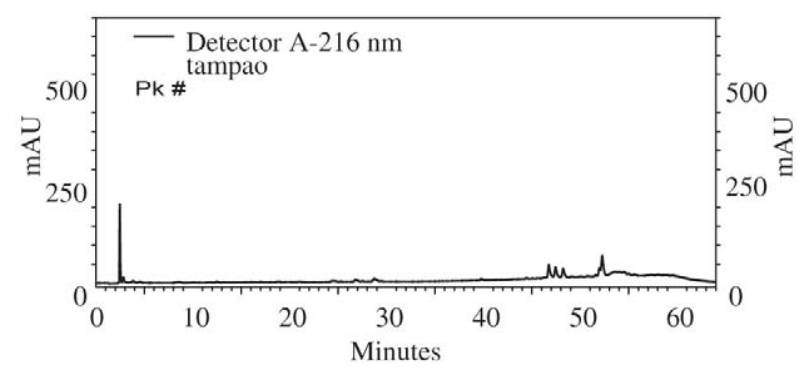

(b)

Figure 1. a) Chromatograms of acid; b) buffer solutions (negative control). 


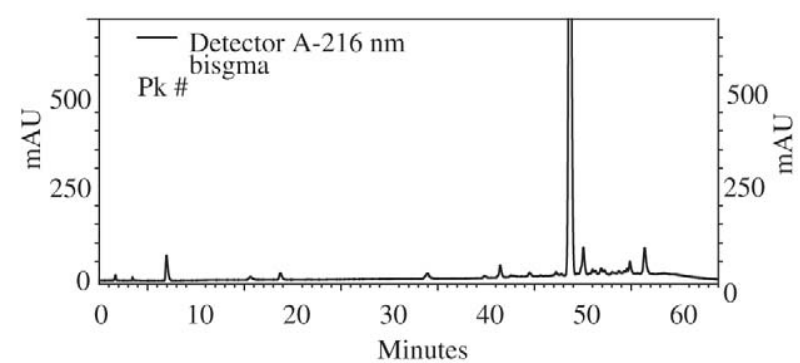

(a)

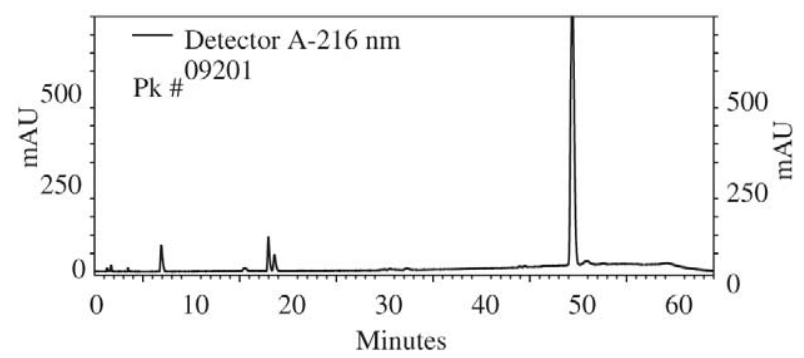

(b)

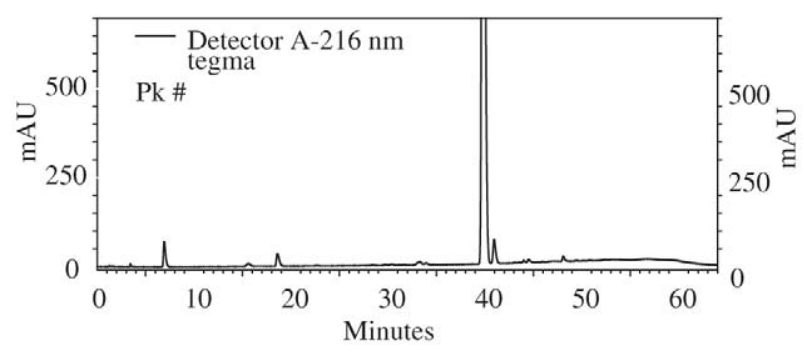

(c)

Figure 2. a) Chromatograms of Bis-GMA; b) UDMA; c) TEGDMA patterns.

erties, the ormocer system must be diluted in a low viscosity monomer, as TEGDMA ${ }^{1}$. The ${ }^{1} \mathrm{H}$ NMR and ${ }^{13} \mathrm{C}$ NMR analysis indicated that the organic fraction was composed by $45 \%$ of BisGMA, $4.2 \%$ of TEGDMA and $50.8 \%$ of UDMA. So, it is able to be degraded like a Bis-GMA resin.

Composite materials have been found not to be biologically inert ${ }^{10}$. The potencial impact that this unpolymerized material may have on the biocompatibility of the resin composite with oral tissues deserves great concern. Study by Olea et al. ${ }^{13}$ has determined that Bis-GMA and bisphenol A leach from dental sealants could cause potencial health hazards by evoking estrogenic responses in tissue culture.

Although, Söderholm \& Mariotti ${ }^{14}$ suggest that the shortterms risk of monomers residues is insignificant, research should be directed at evaluating the phamacokinetics and pharmacodynamics of the long-term release of contaminants from Bis-GMA-based resins used in the mouth.

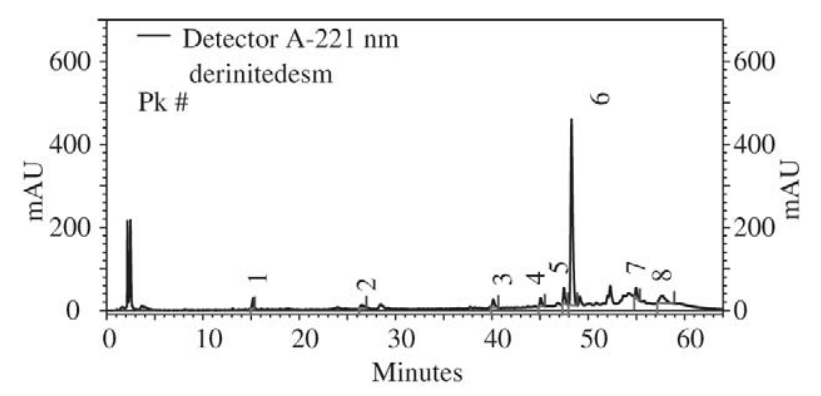

(a)

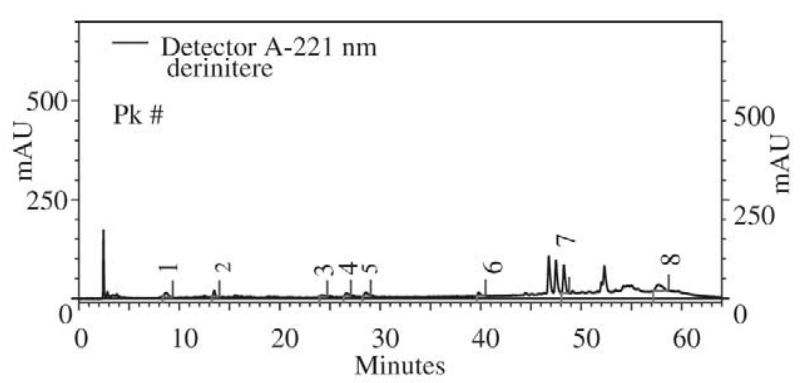

(b)

Figure 3. a) Chromatograms of acid; b) buffer solutions after $\mathrm{pH}$ cycles.

Results prove the importance of oral health education, considering that a high caries challenge environment (low $\mathrm{pH})$ leads to a dental composite degradation, becoming a potential toxicological risk for patients.

\section{Conclusions}

1. The ormocer suffered degradation in a situation of high cariogenic challenge.

2. The $\mathrm{pH}$ has influenced the degradation of the composite, being more significant in the acid environment than in the neutral.

3. After the simulation of high cariogenic challenge, there was a significant alteration on the composite surface.

\section{References}

1. Moszner, N.; Salz, U. Prog. Polym. Sci., v. 26, p. 53576, 2001

2. Elliot, J.E.; Lovell, L.G.; Bowman, C.N. Dental Mater. v. 17, p. 221-29, 2001.

3. Peutzfeldt, A. Eur. J. Oral Sci., v. 105, p. 97-116, 1997.

4. Ferracane, J.L. J Oral Rehabil. v. 21, p. 441-52, 1994.

5. Haas, K-H; Wolter, H. Current Opinion in Solid State \& Material Science, v. 4, p. 571-80, 1999.

6. Modesto, A.; Vieira, A.R.; Chevitarese, O.; Cury, J.A. Rev. ABO Nac., v. 4, n. 5, p. 304-6, 1996.

7. Söderholm, K.J.; Zigan, M.; Ragan, M.; Fischlschweiger., 
J. Dent. Res., v. 63; n. 10; p. 1248-54; 1984.

8. Asmussen, E. Scand. J. Dent. Res., v. 90, p. 490-496, 1982.

9. Lee, S.Y.; Huang, H.M.; Lin, C.Y.; Shih, Y.H. J. Oral Rehabil. v.25, p.575-88, 1998.

10. Muller, H.; Olsson, S.; Söderholm, K-J. Eur J Oral Sci., v. 105 , p. 362-8, 1997.
11. Geurtzen, W. Eur J Oral Sci. v. 106, p. 687-95, 1998.

12. Eliades, G. J Dent., v. 22, p. 73-81, 1994.

13. Olea, N.; Pulgar, R.; Perez, P.; Olea-Serrano, F.; Rivas, A.; Novillo-Fertrell, A.; Pedraza, V.; Soto, A.M. Environ Health Perspect, v. 104, p. 298-305, 1996.

14. Söderholm, K-J; Mariotti, A. JADA, v. 130, p. 201-9, 1999. 